\title{
MANAGEMENT OF WORK RELATIONS
}

\section{Abstract}

Good public administration requires capable workers. This has always been true, but its importance to the local community has probably never been more important than it is today.

The function of human resources management is to provide the employees development of their capability through management system from selection and recruitment to promotion and advancement, benefits, compensation, career development, etc. The function, in terms of the employer's benefit, is to create a management system to achieve long-term goals and plans. The management allows organizations to study, target, and execute long-term employment goals. As well as any real company, the goal of public administration human resource management to have an efficient ability to grow and advance human resource management is a key.

New objectives of human resources (hereinafter - HR) services include the effective implementation of $H R$ policy and coordination of $H R$ management in a government (national and local) organization. Therefore, the responsibilities of HR management and system are starting to embrace a wider range of activities, including the development of labor motivation systems, management of professional promotion, and diagnostic method of auditing in HR management in a public administration. Enhancing efficiency of public administration management, quality of public services they deliver, and implementation of state functions have become the key focus of all broad reforms in the civil service in the Republic of Macedonia.

Key words: human resources, management, public administration, strategic planning, recruitment, works issues, motivation, training.

\section{Introduction}

The term "work relations" is still known as "industrial relations", although, in terms of administration, the first term is more compatible. Work relations refer to a system in which employers, employees, and their representatives, and, directly or indirectly, cooperate in establishing the basic rules for managing labor relations.

This term is used in connection with various forms of labor participation, the individual relationship between the employer and the employee, which relationship is concluded with the signing of the employment contract. The labor 
relations system also incorporates social values such as: freedom of association, a sense of group solidarity, etc.

When analyzing the relationship between human resource management and labor relations, it is necessary to know the basic commitments in establishing and developing the relations worker-work tasks, worker-worker, worker-manager, and worker-organization and worker-union.

The main commitments in establishing solid working relationships in the administration are:

The ultimate goal of the human resources manager in the labor relations system is to create a high capacity of the organization from different profiles of employees, i.e., human resources (capable workers) of the organization, for efficient delivery of policies translated into services as a quality product to citizens. The existence of a public administration and building its own human capital composed of good workers and supported talents is achieved through:

1. Harmonious working relationships - a good human resources manager is committed to the interests of the organization but also to meet the interests and expectations of employees.

2. Determining adequate rules and conditions of employment, in the interest of both the employer, but also the employee, and society as a whole. These conditions are most often achieved by consensus of the social partners: the government, the employer, and the workers' organizations (unions).

3. Establishment of communication mechanisms, employee-employee interaction, employee-supervisor, manager-manager, administrativehuman resource manager, through accepted and established mechanisms and procedures for consultation and cooperation in order to avoid or overcome conflicts and workplace problems and to reach a consensus on labor policies at the national level. Such an example is by determining working hours, overtime work, minimum wage, etc. annual leave, etc.

4. Avoiding violations of already established rules and mechanisms for the protection of labor relations.

5. Construction and implementation of systems to ensure transparency, inclusion, and motivation of all interested in developing interest groups.

Labor relations do not refer only to the sphere of collective labor protection. In practice, employment relationships are often part of the commitment of human resource management and are present from recruitment, team building, communication, and cooperation to the career development of individual workers.

So, human resource management in its essence consists of the following stages: to identify the feelings of employees in relation to the unmet needs they feel, to see ways in which to meet the needs of employees, selection of goals, and common agreement with the employee on how to achieve the same goals, which is important because the feeling of need for motivation is personal and if 
you do not cooperate in a timely manner with the employee, the employee will set his own goals, which may differ from the goals of workplace policy, then, the performance of work, consequences/effects of the work performed and reward or punishment.

The manager is the one who is responsible for the development of human resources, responsible and responsible for developing their potentials and skills, work abilities, and their maximum and proper organization and utilization. Synchronization between the cooperation of administrative managers related to human resources and work responsibilities at the level of the organization, consisting of subsystems of the organization (departments, departments, etc.), participation in resolving all issues related to the rights and obligations of the employee and the conclusion of the employment contract until its termination (recruitment and introduction, training, career building, disciplinary proceedings, retirement, dismissal or dismissal) is related to its most direct tasks in terms of development of the organization. Most often he is responsible for conducting research, measuring work contribution and quality, use of benefits, wage disputes, cooperation with unions, conflicts and conducting disciplinary proceedings, and the like. The manager is always in cooperation with other superiors, managers, department managers, and the like and in accordance with the policies and strategies and strategic planning at the organizational level.

\section{Introduction to work - inductive socialization programs}

The introduction of the new employee or the employee who is assigned to a new job begins with setting the main goal of this phase - strengthening the self-confidence of the employee in the new organization or in the new work environment. This is achieved by reducing the employee's fear that he will not be able to do the job and fit into the team. This in turn can most directly lead to the rejection of the culture and politics of the organization by the employee.

Modern practice in human resource management also indicates that successful socialization - introduction to work is a very important moment that can be reflected for a long time in both positive and negative contexts. Therefore, in order to avoid the negative context in the introduction of new employees in the work environment and tasks, special so-called inductive programs usually from two to three days, when the new employee should be introduced to the superiors and other employees. To this end, terms are agreed in advance with other department managers, to what extent the character of the new employee's work is related to other sectors, and then the new employee is introduced to the workplace, colleagues, and the policy of the staff and organization in a way context with work tasks.

The next thing that is to be achieved in the introduction phase is to generate attitudes towards the organization and the management structure within it and the employee's behavior. If at the earliest stage of introduction in the work, the employee begins to build positive attitudes towards the work envi- 
ronment and the work itself, his behavior will continue to develop throughout his working life and the new employee will develop into a valued worker and colleague. These attitudes should influence the employee to adjust his behavior in order to achieve both his goal and the goals and policies of the organization. Another example could be volunteering, which is mostly conducted once a month and with certain goals.

The process of introducing a new employee has another dimension because it helps to remind other employees from the highest to the lowest rank in the hierarchy that they were once in the position of a new colleague and that they also had their own ambitions and goals. Thus in this process, they have the opportunity to reconsider what and how they have achieved in the past working life in this team.

\section{Performance management ${ }^{1}$}

This phase of human resource management until recently applied exclusively to the private sector and real companies, where the main goal is to improve company productivity by managing the performance of work efficiently. Now in the EU and modern public administrations, the overall reforms are based on a competitively oriented administration and this is done with good performance or performance at work.

It starts with the performance-oriented way of thinking and the performance. This is followed by the phase of establishing understandable and established performance standards, monitoring and providing feedback, assessment.

Then a plan is made at the beginning and end of the supervised period.

Performance expectations are the basis for evaluating employee performance. The standards outline the basic line for measuring performance. The standards provide feedback that will describe the gap between expected and actual performance.

Well-set standards are an objective basis for evaluating the performance of work, it provides employees with familiarity with acceptable and unacceptable results, employees are satisfied when they know that tasks are performed well, new employees through the standards are informed about expectations about job performance.

The basic terms used to describe the performance are:

- Quantity - expresses how much work needs to be done in a given period. Until recently, this parameter was considered not to be applicable in administrative work, but this situation has changed with the orientation of the competence of the administration;

- Quality - this term describes how well a job is done. For example, 95\% of documents prepared by an administrative employee are accepted without objection or correction.

\footnotetext{
$\overline{1 / / \text { www.oshr.nc.gov }}$
} 
- Time frame - represents a certain time (from - to) during which one thing needs to be done.

- Effective use of resources - used when the performance of work is observed through the effective use of resources: saving money, waste, etc.

- Manner of engagement - describes the conditions when the personal behavior of the employee affects the performance of the work, e.g. an employee finishes his work well and ahead of time or the situation is such that at the moment of measurement he is not overworked and uses his working time to help his colleagues, and thus $100 \%$ of the working time is engaged.

- Manner of work - describes the conditions when one employee's behavior affects the work of others (hires other employees to complete the task).

- Work according to prescribed procedures and routines - this module is used when a routine is prescribed for one job, so it is measured how much the employee manages to complete the work and with what quality without going out of routines.

\section{Ways of monitoring the performance of the work}

The most common ways of effective performance monitoring and verification are:

- Direct observation;

- Specific results (sensitive evidence that may be subject to audit without the officer being present.

- Submission of reports and recordings, such as regularity reports, safety at work, financially productive operation, etc.

- Collecting constructive criticism of the employee's work (positive or negative).

\section{Feedback}

Employees need both as receiving and transmitting important information, in order to strengthen their contribution to the success of the organization which in turn leads to increased benefits for them. Such transmissions of information can be applied in a situation where the results of the work are not as expected and the reasons for this are either little known and unstable or not known at all.

Feedback, hereinafter referred to as "feedback", needs to be well-conceived and employees trained to best exchange specific information. Feedback differs from standard communication because it is most closely related to understanding situations of good or bad job performance. Moss, as part of the research team, gave a detailed description of the theoretical foundations for 
strategic approaches to managing feedback. The theory is that it explains how employees view their work (well done or poorly done), then share their impressions with their supervisor and point out a good performance.

The most direct benefit is to increase their ability to build on their own and the work of others, to improve their personal responsibility, and to create opportunities to realize their individual, group, and collective desired benefits. Employees are trained to critically reflect on their work results, possibly to present some circumstances, objective and subjective, which according to them influenced the realization of their work tasks. They themselves set a lower performance threshold and send and receive (exchange) information with their supervisor and human resources manager on how to improve their performance and reach the lower performance threshold required to improve their performance. Or, how to maintain good performance and improve. Feedback also refers to the reaction of employees to certain behaviors and situations in the organization, and very often to their expected benefits or penalties.

This approach allows not to hurt the ego of employees through insults and punishments but to understand the situation and circumstances from all parties involved and jointly set strategic short-term goals and methods for achieving them.

Practice shows that properly performed feedback overcomes the most common situation of poorly performing employees refusing to communicate with their superiors and locating their negative energy on the work they do, the users of their services, and the organization in which they are employed.

Effective feedback management is best done by the human resources manager because the staff accepts him as a supervisor who can help but can not punish them because it is the responsibility of their immediate supervisor. The manager has a role here to explain the situation to them but at the same time to open two-way communication channels. With it, employees discuss their personal reasons for their poor performance, learn to be self-critical in self-assessment, but also to be objective about the conditions, disappointment, inappropriate and imposed performance thresholds, and the like.

In order for the feedback to work, it is necessary for the human resources manager to establish a clear procedure and persons involved in the realization of the feedback (collecting, giving, and evaluating data). Feedback can be in writing, which is most often used in larger collectives, where the questions are of semi-open or open type, and direct form, which in turn proves to be most effective because it establishes a relationship of trust and cooperation, even partnership between employee and manager for human resources or its representative. The overall result is that employees become much more objective about the current situation and develop a sense of partnership with superiors to improve the personal and organizational results of the organization. The effect is that the employee returns to a standard attitude towards his job, more precisely, reconciles and feels motivated and responsible to improve his performance expecting agreed benefits and incentives. Feedback can also be treated 
as two-way teaching. The training is equated with the evaluation of the training by the participants.

From the schematic of the manager's circle of responsibilities, it can be seen that management starts by setting clear goals, then measuring performance, receiving feedback on results and determining incentive rewards based on them, and finally, evaluating the set goals, the activities that lead to their realization and the products. The circle is closed by setting goals again.

\section{Figure 1.}

Setting the Circle of Manager Responsibilities ${ }^{2}$

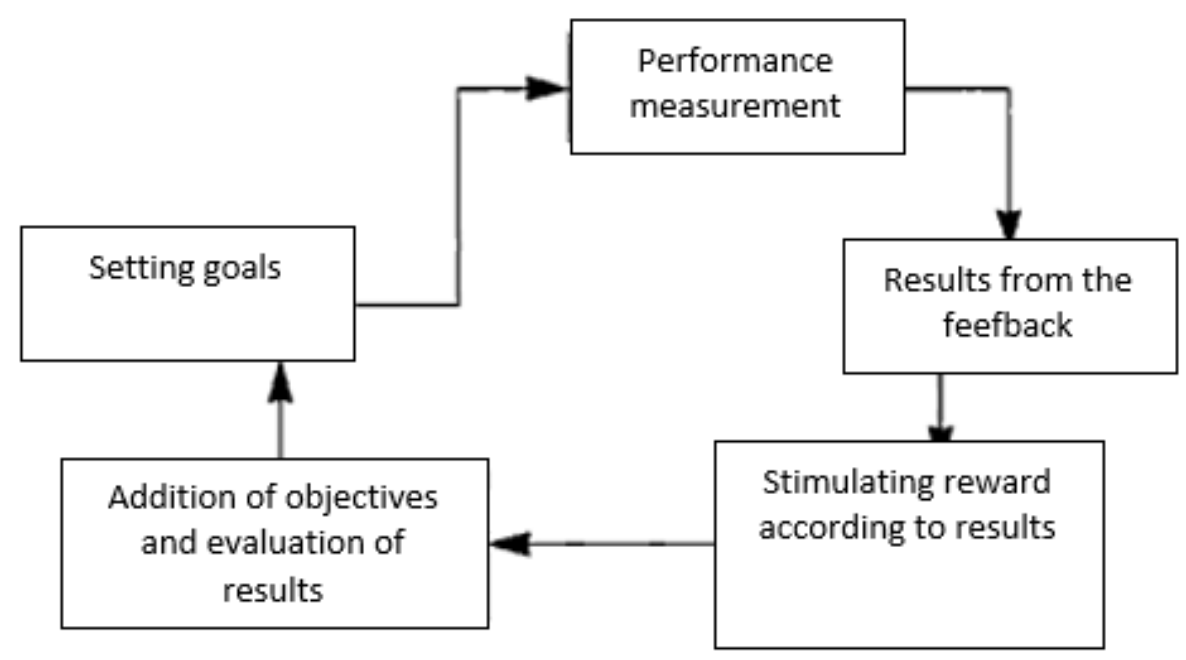

\section{Training and assessments/evaluation}

The best training (teaching) occurs when no more than two aspects of the job chain are involved in the discussion. This strengthens self-confidence and motivates the employee as a professionally responsible person. Here, unlike other systems of case analysis, the officer feels he has the support of his superior in his progress.

In training, which is most often applied when it is necessary to pay attention to some specific aspects of the work of the officer. Successful training is when there is feedback from other employees, to analyze in detail the successful performances of the employees as well as those who are not successful and to

2 "Performance Management Cycle". University of California, Berkely, Center for Organizational and Workspace Effectoveness, http://hrweb.berkeley.edu/files/attachments/ Performance-Management-Toolkit.pdf 
compare, to point out alternative solutions to the employee, the employee to be timely advised before the assessment and to be explained what and how it is assessed and have his consent, thus providing an interactive role. Good practice shows that documenting sessions can be a great example for the next session.

The most successful is the training when the employee has confidence in the coach and their communication is solid.

The evaluation of the work is part of the process of human resource management and provides an excellent opportunity to evaluate the work done so far and how satisfactory the work of an employee is. It is especially important to consider assessment in strategic and development planning. It should summarize the employee's current commitment and quality throughout the assessment period (usually one year) and should not be treated as part of the employee discipline process.

The objectives of job evaluation are:

- To help the employee to have a positive attitude towards his work;

- To be motivated to be interested in working well and to be ready to develop their performance;

- To get constructive feedback;

- The employee to be involved in the development process.

The officer may be asked to write an assessment of his/her own work by being given a specific questionnaire or instructions on how to perform the self-evaluation. There are many techniques for preparing the assessment, but usually, everyone prepares a scheme of points at which the work will be evaluated, e.g. job description and difficulty of work, standards for performing the work established when the employee has accepted it, samples of his work or documentation for an initiated disciplinary procedure. In modern practice, evaluation is not treated as intimidation of the employee but as a way to help him improve his work, or to reward him for good performance of work and tasks. It is very important for both the human resources manager and the workplace to produce documentation from the evaluation with a longer shelf life in the human resources department as personal documents of the employee. These documents should also be protected and made exclusively available to those most responsible or designated by them. The officer must have a copy of the final grade or this documentation. It is common practice to set up a performance management system, usually composed of the following components:

- Accountability of execution - especially characteristic of the public sector and refers to the execution of a job to be similar, not unified but similar and recognizable as in all democracies with a similar democratic order.

- Execution through feedback from service users, similar to pricing a product. Indices for evaluating services are prepared here and they are an important indicator and measure for a possible need for change, as there are three aspects of measurement, namely timeline, accessibility, and quality. 
- Effective execution that focuses on internal efficiency from input to output, i.e., when local top people and councils make decisions.

\section{Salaries and allowances}

The term salaries means: the basic monetary compensations for the work performed (salaries), the salary increases, and the bonuses. They are determined by complex factors such as the characteristics of the organization. They are an important and effective motivating factor in the performance of work tasks and the behavior of human resources in the organization.

Wages in theory are part of the compensation for the work invested and are at the center of labor relations and are critical for both employers and workers, in this case, employees. Employees, most often, make their living with them, so it is normal to make special efforts to increase their income.

The most common practice is to organize wages into payment systems that cover the format, level, structure, and administration of payment. ${ }^{3}$

Regarding the payment, the most commonly applied way is for the payment to be after the work performed ${ }^{4}$, and the employee to accept the payment of the reward as personal progress. If he is paid a salary that is not commensurate with the quality and quantity of his work in the future, the effect on the work of the same worker will be smaller.

Wage level: is a broad comparative concept of how the organization forms wages and what is the level compared to other similar organizations.

The structure of payments is usually in accordance with the hierarchy of jobs and positions in the organization, coefficients for categorization of responsibility, weight, required skills, working hours (with the factor of effective working hours), work experience, education, working conditions, and so on.

\section{CONCLUSION}

Human resource management is a complex subject for which there is good theoretical support. In the last two decades, human resource management in public administration has become one of the priority areas followed by thorough reforms in order to comply with the standards and norms applied in the European Common Administrative Space.

In the Republic of North Macedonia, a solid legal basis has been created to strengthen human resource management. Strategic planning is a method that is the basis of human resource management from recruitment, selection, employment, motivation, information and communication, cross-sectoral cooperation between department and department managers, training as part of

\footnotetext{
${ }^{3}$ Gerhart \& Milkovich, 1992; Heneman \& Schwab, 1979; Milkovich \& Newman, 1993

${ }^{4}$ Законот на Ефект на Торндаик Nevin, John (1999). "Analyzing Thorndike's Law of Effect: The Question of Stimulus - Response Bonds". Journal of the Experiment Analysis of Behaviour. p. 448.
} 
organizational development strategies, career and talent management, and of course teamwork.

Putting above all, the right approach and attitude towards human resource management based on scientific theories provides an excellent opportunity to strengthen primarily the management structures which in turn greatly influence the strengthening of human resources.

\section{Literature:}

"Performance Management Cycle". University of California, Berkeley, Center for Organizational and Workspace Effectoveness, https://dl.icdst.org/ pdfs/files/08dca929258df3c1ee9a1f7be2598405.pdf

Bach, S. and Edwards, R.M. (2012). Managing Human Resources: Human Resource Management in Transition. John Wiley \& Sons Ltd.

Nevin, J. (1999). “Analyzing Thorndike's Law of Effect: The Question of Stimulus - Response Bonds". Journal of the Experiment Analysis of Behaviour. p. 448.

Sherry E. M. \& Juan I. S. (2004), "Are your employees avoiding you? Managerial strategies for closing the feedback gap", Academy of Management Executive, Vol. 18, No. 1

www.oshr.nc.gov 